\title{
Protective Effect of Andrographis paniculata Against Atrazine Induced Renotoxicity in Albino Rats
}

\author{
Shirisha $\mathrm{K}^{1}$, B .Salma Begum ${ }^{2}$,Mastan $\mathrm{M}^{3}$ \\ ${ }_{1,2,3}$ Department of Biotechnology, Dravidian university, Kuppam-517426, A.P India
}

\begin{abstract}
Andrographis paniculata is (AP) a medicinal plant that has been effectively used in traditional Asian medicines for centuries. Its major constituents are diterpenoids, flavonoids and polyphenols. The efficiency of Andrographis paniculata ethanolic extract was studied on atrazine induced renotoxicity in male wistar albino rats. All the oxidative and antioxidative enzymes, malondialdehyde, superoxide dismutase, glutathione peroxidase, catalase, glutathione-s-transferase, reduced glutathione were estimated by standard protocols. Ethanolic extract of AP $(150 \mathrm{mg} / \mathrm{kg} \mathrm{bw})$ was found to protect the rats from renotoxic action of atrazine as evidence by decreased in the level of lipid peroxidation and increased the activities of antioxidant enzymes in the kidney. In addition the ethanolic extract prevented the toxicity of kidney from atrazine exposure. The antioxidant activity of AP suggests it as potential antioxidant against atrazine induced oxidative stress.
\end{abstract}

KEY WORDS: Renotoxicity, wistar albino rats, antioxidant enzymes, Atrazine, Andrographis paniculata (AP).

\section{INTRODUCTION}

Atrazine (2-chloro-4-ethylamino-6-isopropylamino-1,3,5-triazine) is a member of s- triazine group of herbicides. It is a chlorotriazine herbicide is used extensively in United States. Atrazine exposure cause detrimental effects, eyes and nose irritation (Stevens, Sumner 1991) [1]. It is mainly used for post and preemergence control of annual grass and broad-leafed weeds in maize, sorghum, macadamia nuts, other crops and sold in different commercial names like Aatrex, Aatratol, Bicap, Gasaprin (Tomlin 1994) [2]. Atrazine has been shown to cause liver, kidney and heart damage in animals and is therefore likely to cause the same in humans (ATSDR 2003) [3]. Singh et al. reported that reduced glutathione (GSH) content of the erythrocytes of atrazine treated rats was decreased as compared to control group triazine (Singh et al., 2010) [4]. Co-administration of Andrographis paniculata (AP) along with atrazine restored the GSH content of erythrocytes nearly to the control levels. In humans and other animals, Atrazine causes skin, light sensitivity, respiration disorder, paralysis, organs weakening, specially arms and legs, chemical structural modification in the brain, liver, heart, lung, kidney, ovary and delay growth of endocrine organs (Chan et al., 2006, Li et al., 2006) [5]. Oxidative stress in biological systems due to effect of pesticides originates as the result of an imbalance between the generation of oxidizing species and cellular antioxidant defences (El- Shenawy 2009, El- Shenawy 2010) [6]. Numerous enzymatic mechanisms take place to protect the cell against oxidative damage. The radical chain reaction of lipid peroxidation (LPO) appears to be a continuous physiological process. This process, if out of control, can alter essential cell functions and lead to cell death (Kappus 1987) [7]. Endogenous antioxidants in medicinal herbs may play an important role in antioxidant defense against oxidative damage, possibly protecting the biological functions of cells (Gunther 2004) [8]. There is increasing interest in the protective biological function of natural antioxidants contained medicinal herbs all over the world, which are candidates for the prevention of oxidative damage. Now-a-days many natural products are used in therapy of different diseases. Andrographis paniculata commonly known as 'kalmegh' in India, is used as a bitter constituent in 26 Ayurvedic formulations as immunomodulatory (Xu, Chen, Fry, Barrow et al., 2007) [9], antiangiogenic (Sheeja et al., 2007) [10], anticancer (Kumar et al., 2004) [11], antiviral (Calabrese et al., 2000) [12] and antibacterial (Singha et al., 2003)[13]. The goal of the present study was, therefore, to investigate the beneficial role of Andrographis paniculata against atrazine toxicity in kidney. In addition, the prooxidant - antioxidant status of kidney tissue were determined by measuring the level of the end product of lipid peroxidation (LPO), the activities of the intracellular antioxidant enzymes namely, superoxide dismutase (SOD), catalase (CAT), glutathione-stransferase (GST) and glutathione peroxidase (GPx) as well as by determining the level of reduced glutathione (GSH). In the present investigation AP has the potential to attenuate atrazine induced oxidative stress.

II. MATERIAL AND METHODS

The entire chemicals including Atrazine were obtained from Sigma Aldrich chemicals. 


\section{Plant Material}

The plant material was collected from Herbal Garden Dravidian University, Kuppam. The Voucher specimen was identified with the help of local and regional floras. Sample was shade dried and pulverized in mechanical grinder and stored in an airtight container till further successive extraction.

Animals

Male albino rats (Wistar strain,) weighing about 200-230g was used throughout the studies. The animals were housed in polypropylene cages provided with water and standard pellet diet adlibitum.

\section{Preparation of Ethanolic extract}

The dried powder extracted in a Soxhlet apparatus using ethanol at a temperature range of $55^{\circ} \mathrm{C}$ to $60^{\circ} \mathrm{C}$. The filtrate was evaporated to dryness at reduced pressure in vaccum evaporator.

\section{Experimental design}

Animals were segregated in to four groups with each group having 6 animals. Animals in each group were treated with Atrazine and Andrographis paniculata daily for a period of 7 and 14 days as described below. Atrazine was given at a dose of $300 \mathrm{mg} / \mathrm{kg}$ body weight. The dose of Andrographis paniculata is $150 \mathrm{mg} / \mathrm{kg}$ body weight.

Control: Animals treated with only saline through orally

Atrazine treated: Animals were given Atrazine (300 mg/kg body weight) dissolved in saline through orally. Andrographis paniculata treated: Animals were given Andrographis paniculata (150 $\mathrm{mg} / \mathrm{kg}$ body weight) dissolved in water.

Atrazine + Andrographis paniculata treated: Animals were given Atrazine $(300 \mathrm{mg} / \mathrm{kg}$ body weight) along with Andrographis paniculata $(150 \mathrm{mg} / \mathrm{kg}$ body weight) dissolved in saline and water.

\section{Sample collection}

At the end of 7 days and 14 days, overnight fasted rats were sacrificed. Kidneys of the animals were removed, rinsed in ice cold isotonic saline $(0.9 \% \mathrm{w} / \mathrm{v} \mathrm{NaCl})$, blotted dry, weighed and stored at $-40^{\circ} \mathrm{C}$ for further work.

\section{Preparation of samples}

A $10 \%(\mathrm{w} / \mathrm{v})$ tissue homogenate was prepared in 50mM Tris HCL $\left(\mathrm{P}^{\mathrm{H}} 7.4\right)$ using homogenizer. A Post mitochondrial supernatant (PMS) was prepared by centrifuging the homogenate at 10,000 rpm for $10 \mathrm{~min}$ at $4^{0} \mathrm{C}$. The pellet was discarded and supernatant thus obtained was referred to as PMS. Various biochemical parameters were assayed in the homogenate and post mitochondrial supernatant of rat kidney.

\section{Protein estimation:}

Protein content was determined according to Lowry method (1951) using bovine serum albumin as a standard.

\section{Lipidperoxidation (LPO)}

The level of lipid peroxidation in the tissues was measured in terms of malondialdehyde (MDA; a product of lipid peroxidation content and determined by using the thiobarbutaric acid reagent (TBA) reagent. The reactivity of TBA is determined with minor modifications of the method adopted by Hiroshi et al (1979). The organic layers was transferred in to a clear tube and its absorbance was measured at $532 \mathrm{~nm}$. The rate of lipid peroxidation was expressed as $\mu$ moles of malondialdehyde formed/g wet wt. of tissue .

\section{Antioxidant enzymes \\ Reduced glutathione (GSH)}

GSH activity in the selected tissue was assayed by the method of Ellaman et al. (1961). Samples were deprotonated by sulfosalicyclic acid followed by the reaction of sulfhydryl groups of glutathione with DTNB (5,5'- dithiobis-2-nitrobenzoic acid) to produce a yellow coloured product 5-thio-2-nitrobenzoic acid. The reaction is read at $412 \mathrm{~nm}$. The results were expressed as $\mathrm{n}$ mol GSH/mg protein.

\section{Superoxide dismutase (SOD)}

SOD activity was determined by using the epinephrine assay of Misra and Fridovich (1972). At alkaline $\mathrm{P}^{\mathrm{H}}$, superoxide anion $\mathrm{O}_{2}$ - causes the autooxidation of epinephrine adenochrome; while completing the 
reaction of SOD decreased the adenochrome formation and changes in absorbance were recorded at $480 \mathrm{~nm}$, measured at 10sec intervals for $1 \mathrm{~min}$ in spectrophotometer.

\section{Catalase (CAT)}

Catalase activity in the selected tissues was assayed by the method of Chance and Machly (1955). The decomposition of hydrogen peroxide was followed directly by measuring the decrease in absorbance at $240 \mathrm{~nm}$, at $10 \mathrm{sec}$ intervals for $1 \mathrm{~min}$ in spectrophotometer (Hitachi model,U-2001).The catalase activity was expressed as $\mathrm{n}$ moles of hydrogen peroxide metabolised $/ \mathrm{mg} \mathrm{ptn/min}$.

\section{Glutathione peroxidase (GPx)}

It was measured by the method of Rotruck et al. To the enzyme source EDTA, sodiumazide, glutathione reduced, hydrogen peroxide buffer is added at $37^{\circ} \mathrm{c}$ for $10 \mathrm{~min}$. The reaction was arrested by adding TCA. The reaction was read at $412 \mathrm{~nm}$ in spectrophotometer.

\section{Glutathione-s-transferase (GST)}

GST activity in the cytosol fraction of the selected tissues was assayed by using 1-chloro 2, 4dinitrobenzene (CDNB) at 340nm) substrate as described by Habig et al 1974.

\section{RESULTS}

Rats which received Atrazine alone showed a marked decrease in body weight accompanied by a significant increase in markers like SOD, GPx CAT and etc., which are shown in Table 1 and Figure 1. Administration of Atrazine alone significantly increases the lipid peroxides in rat kidney $(6.32 \pm 0.8)$ when compared to normal (3.62 \pm 0.4$)$ and the combination of Atrazine with Andrographis paniculata (AP) treated rats $(5.72 \pm 1.4)$ (Table 2). The elevated lipid peroxidation was significantly decreased in rats treated only with AP (4.98 \pm 1.2 ).In the present study, the antioxidant enzyme levels (SOD, GPx, CAT, LPO, GST and GSH) of rat kidney were significantly increased in group I when compared with group II and III. When compared with control group, the antioxidant enzyme levels were also increased in group II and III but not that much increase like group. In all the cases time dependent increase was observed following atrazine exposure. Maximum increase was observed after 14days of the administration.

Tables: Mean values of Antioxidant enzymes in Atrazine induced oxidative stress in rat kidney

\begin{tabular}{|l|l|l|l|l|}
\hline \multirow{2}{*}{ Parameters } & \multicolumn{4}{|l|}{ Treatment Groups } \\
\cline { 2 - 5 } & Control & At & AP & At+AP \\
\hline SOD & $58.03 \pm 2.3$ & $62.34 \pm 1.8$ & $55.24 \pm 2.4$ & $60.48 \pm 2.3$ \\
\hline GPx & $168.24 \pm 5.4$ & $176.75 \pm 4.9$ & $170.45 \pm 3.6$ & $174.85 \pm 3.2$ \\
\hline CAT & $65.41 \pm 1.2$ & $72.24 \pm 1.3$ & $67.58 \pm 1.4$ & $70.52 \pm 1.2$ \\
\hline GST & $124.12 \pm 6.3$ & $132.41 \pm 5.4$ & $129.43 \pm 4.5$ & $130.27 \pm 3.2$ \\
\hline GSH & $11.24 \pm 1.4$ & $15.96 \pm 1.2$ & $12.47 \pm 2.3$ & $14.18 \pm 1.8$ \\
\hline LPO & $3.62 \pm 0.4$ & $6.32 \pm 0.8$ & $4.98 \pm 1.2$ & $5.72 \pm 1.4$ \\
\hline
\end{tabular}

Note: SOD: Superoxide dismutase

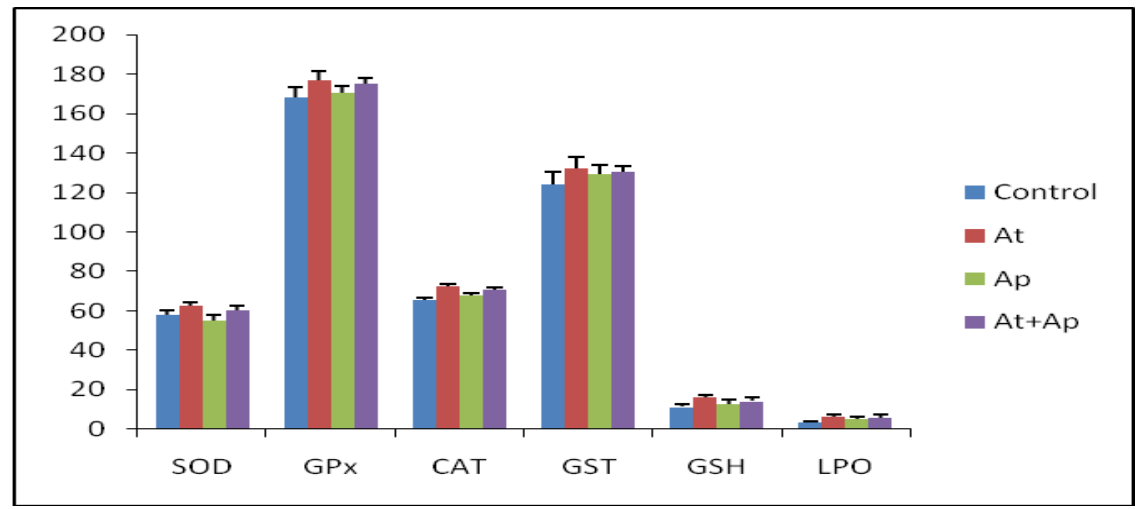

Figure1. Antioxidant enzymes in Atrazine induced oxidative stress in rats 


\section{DISCUSSION}

This study suggests that atrazine to induce oxidative stress and its possible attenuation by AP in kidney of rat. Experimental animals were administered atrazine and AP oral dose for a period of 7 and 14 days. Results indicated that the GSH content and antioxidant power of the renotoxicity of atrazine treated rats were increased as compared to the control group. Co-administration of AP along with atrazine restored the GSH content and antioxidant power level of kidney tissue nearly to control levels. Antioxidant is a substance that delays or inhibits oxidative damage to target molecules (Halliwell B (1996) (14). The activities of antioxidant enzymes such as SOD and CAT were found to be increased in the kidney tissue accompanied by increase in the activity of GST, following atrazine exposure. In our study, one of most prominent changes in CAT, SOD, GSH, GST and GPx activity was seen in renal tissues. Atrazine administration increased in lipid peroxides in kidney when compared to control group. Hydrogen peroxide is neutralized by the combined action of cat and glutathione peroxidase in all vertebrates (Masella et al (2005) (15). These enzymes are coordinated and the cells may be provoked to oxidative stress of any changes occurs in the level of enzymes. In the present study, the administration of atrazine alone increases the LPO in rat kidney when compared to normal group.

Further, GST provides protection to the tissues by catalysing the conjugation reactions between GSH and electrophilic xenobiotics (Mulder et al 1990) (16). The inverse correlation obtained in the present study between GSH and GST shows that the activity of the enzyme increases. Therefore the results indicated that the atrazine might generate free radicals that reacted with membrane lipids and induced oxidative break down of membrane structure and decreased the enzymatic antioxidant.

In the other hand, when AP was co-administered along with atrazine, activities of enzymes restored. The aqueous extract of AP could considerably alleviate the nephrotoxic action of Gentamicin in male albino rats, thus exhibiting marked renoprotective activity (P Singh et al (2009) (17). The results in the present study showed that AP was scavenging free radical by its potent antioxidant. Andrographolide, is the major chemical constituent of the plant. AP has been reported to possess antioxidant activity. LPO decreases in in rats treated only with AP. The antioxidant enzyme levels of SOD, CAT, GST, GPx, GSH increases in normal group of rats when compared to atrazine and AP treated rats. When compared with normal group, the enzyme levels were also increases in atrazine and AP treated rats but not much increased in normal group. In all the cases time dependent increase was observed following atrazine exposure. Maximum increase was observed after 14 days of the administration. The results indicated that the possible involvement of free radicals in atrazine -induced toxicity and highlights the protective action of AP.

\section{CONCLUSION}

Results of study demonstrated that atrazine induced oxidative stress in rat kidney, increased activities of the various antioxidant enzymes and decreased content of LPO and antioxidant power. However, AP administration ameliorated the effects of atrazine, suggesting that AP is a prospective antioxidant against atrazine-induced oxidative stress.

\section{ACKNOWLEDGEMENT}

The first author extends her thanks to UGC-Non-SAP (BSR), New Delhi fellowship for providing financial assistance.

\section{REFERENCES}

[1] Stevens JT, Sumner DD (1991) Herbicides, in Handbook of pesticide technology, by Hayes, WR Jr, Laws ER Jr (eds.) Academic Press, New York.

[2] Tomlin C (1994) Pesticide Manual, 10th Edition, British Crop Protection Council, The Royal Society of Chemistry

[3] ATSDR (2003) Toxicological Profile for Atrazine, pp. 5.

[4] Singh M, Sandhir R, Kiran R (2010) Oxidative stress induced by atrazine in rat erythrocytes: Mitigating effect of vitamin E. Toxicol Mechan Meth 20 (3):119-12

[5] Chan, YC.; Chang, SC.; Hsuan, SL.; Chien, MS.; Lee, WC.; Kang, JJ.; Wang, SC. and Liao, JW.(2007). Cardiovascular effects of herbicides and formulated adjuvants on isolated rat aorta and heart. Toxicol In Vitro. 21(4):595-603. Epub 2006 Dec22

[6] Li A, May MP, Bigelow JC. (2006). Identification of a metabolite of atrazine, N ethyl - 6 methoxy - N'- (1-methylethyl)- 1, 3, 5triazine- 2, 4- diamine, upon incubation with rat liver microsomes. J Chromatogr B Analyt Technol Biomed Life Sci. 19; 836(1-

[7] El-Shenawy NS (2009) Oxidative stress responses of rats exposed to Round up and its active ingredient glyphosate. Environ Toxicol Pharmacol 28: 379-385 El-Shenawy NS (2010) Effects of insecticides fenitrothion, endosulfan and abamectin

[8] on antioxidant parameters of isolated rat hepatocytes. Toxicol in Vitro 24: 1148-1157.

[9] Kappus H (1987) Oxidative stress in chemical toxicity. Arch Toxicol 60: 144-149.

[10] Gunther MR (2004) Probing the free radicals formed in the metmyoglobin hydrogen peroxide reaction. Free Radic Biol Med 36: 1345-1354.

[11] Xu Y, Chen A, Fry S, Barrow RA, Marshall RL, Mukkur TKS. Modulation of immune 
response in mice immunised with an inactivated Salmonella vaccine and gavaged with Andrographis paniculata extract or andrographolide. Int Immunopharmacol. 2007;7:515-23 [10] Sheeja K, Guruvayoorappan C, Kuttan G. Antiangiogenic activity of Andrographis paniculata extract and andrographolide. Int Immunopharmacol. 2007;7:211-21.

[12] Kumar RA, Sridevi K, Kumar NV, Nanduri S, Rajagopal S. Anticancer and immunostimulatory compounds from Andrographis paniculata. J Ethnopharm. 2004;92:291-5.

[13] C. Calabrese, S. H. Berman, J. G. Babish et al., "A phase I trial of andrographolide in HIV positive patients and normal volunteers,” Phytotheraphy Research, vol. 14, no. 5, pp. 333-338, 2000.

[14] P. K. Singha, S. Roy, and S. Dey, “Antimicrobial activity of Andrographis paniculata,” Fitoterapia, vol. 74, no. 7-8, pp. 692$694,2003$.

[15] Halliwell B (1996) Antioxidant in human health and disease. Annu Rev Nut 16:33-38

[16] Masella R, Di Benedetto R, Vari R, Filesi C, Giovannini C (2005) Novel mechanisms of natural antioxidant compounds in biological systems: involvement of glutathione and glutathione - related enzymes. J Nutrit Biochem 16 (10): 577 - 586.

[17] Mulder GJ, Adang AEP, Brussee J, Ketterer B, Meyer D, et al. (1990) The glutathione binding site glutathione S-transferase isoenzymes from the rat: selectively towards tripeptide analogues of glutathione. Glutathione S-transferase and Drug Resistance Taylor \& Francis, Great Britai p. 75.

[18] P. Singh, M. M. Srivastava, and L. D. Khemani, "Renoprotective effects of Andrographis paniculata (Burm. f.) Nees in rats," Upsala Journal of Medical Sciences, vol. 114, no. 3, pp. 136-139, 2009. 